\title{
First European Conference on the Physics of Condensed Matter
}

\section{S. F. Edwards}

On the invitation of the Structure of Materials Section of the Italian Research Council, the Condensed Matter Division held a major meeting at Florence on 14-17 September 1971. At the well-supported conference attended by about 600 delegates some eight plenary and 24 sectional invited papers were presented in addition to about 170 contributed papers. The pattern was broadly similar to that of meetings of the American Physical Society, with four parallel sessions for the contributed papers. Although contributions in all branches of Condensed Matter were accepted, the majority of papers came under the main headings of "metals" as material and phase "transformation" as a phenomenon. A good attendance was maintained notwithstanding the delights of Florence, and the new $\mathrm{Pa}$ lazzo dei Congressi served the meeting well, though it would clearly be very difficult ever to accommodate meetings on the scale of the American Physical Society anywhere in Europe.

Since only eight of the invited papers, a quarter of the total, were presented at plenary sessions of the Conference, a brief report on these alone will be given.

H. Thomas (Frankfurt) introduced the topic of phase transitions, showing how their dynamics could be understood by first considering them in the light of the simplest approximations and then revising ideas in view of the failure of the simple approach.

G. Busch and H.G. Güntherodt ( $\mathrm{Zu}-$ rich) reviewed liquid metals and showed that, unlike phase changes, the central problems appear to be solved and the main emphasis now rests on tidying up the details, particularly of the transition elements. This led to a lively discussion which was revived in a later paper presented by J. Friedel (Paris).

P.G. de Gennes (Orsay) gave an account of liquid crystals; there too a basic understanding has been achieved but many related phenomena are still being discovered and interpreted. The hydrodynamics of these systems represent a world of great complexity.

B. Sestak (Prague) reviewed the current situation in plastic deformation, showing how f.c.c. metals are really quite well understood, whereas b.c.c. metals pose complicated technical problems.

W. Albers (Eindhoven) discussed composite materials, in particular those grown from eutectic mixtures. After presenting some quite simple theories he showed a series of impressive and convincing photographs of such materials in formation and fully formed under various conditions, and explained their technological importance.

U. Essmann (Stuttgart) also showed very impressive pictures in his talk on correlations and interactions between flux line lattices and crystal lattices. While the origin of these lines is understood, experiments on their mutual interactions clearly show behaviour that still requires a theoretical understanding.

V.G. Skobov (Leningrad) took the
Conference through the richness of detail predicted for the electromagnetic waves of the electron gas of metals. It was clear from the successes achieved that this subject is moving into the realm of applied physics or even electrical engineering.

P. Goy (Paris), who followed, described the remarkably successful studies of cyclotron resonance at high frequencies. The use of the millimetre and sub-millimetre bands proves to be most fruitful for investigating the nature of the electron-phonon interaction, particulary in $\mathrm{Pb}$.

Your reporter found himself moving from room to room during the parallel sessions and will content himself to say that there was much of interest coupled with lively discussions.

During the Conference the opportunity was taken to hold a business meeting at which delegates could voice their opinions on how the Division, and indeed the EPS, were going. It was fortunate to have the President and Executive Secretary present. After the President's introductory remarks on the progress of the EPS a lively discussion developed about the activities of the Division and, in particular, about the organization of conferences. One school of thought would relegate contributed papers to reading by title or to total abolition, whilst other speakers stressed the importance of the acceptance of papers to secure allocation of expense allowances, but stronger rules and refereeing were suggested. Some changes are advis- 
able and the discussion will be remembered : what about some correspondence on this topic in Europhysics News?

A three-year interval for big meetings was felt to be reasonable, although at the outset a shorter period might be justified; also a balance between East and West was needed. The policy of the EPS Conference Committee in encouraging Europhysics Study (i.e. Gordon type) Conferences met with approval, as did the general form of the Division and its sections (of which Magnetism and Metals met on the occasion of the Conference).

The event was a good inauguration for the Division, and the Physics Department at Genoa under G. Boato is to be congratulated on its organization.
Physics is Fun! Left to right: S.F. Edwards, S.O. Lundqvist, G. Busch.
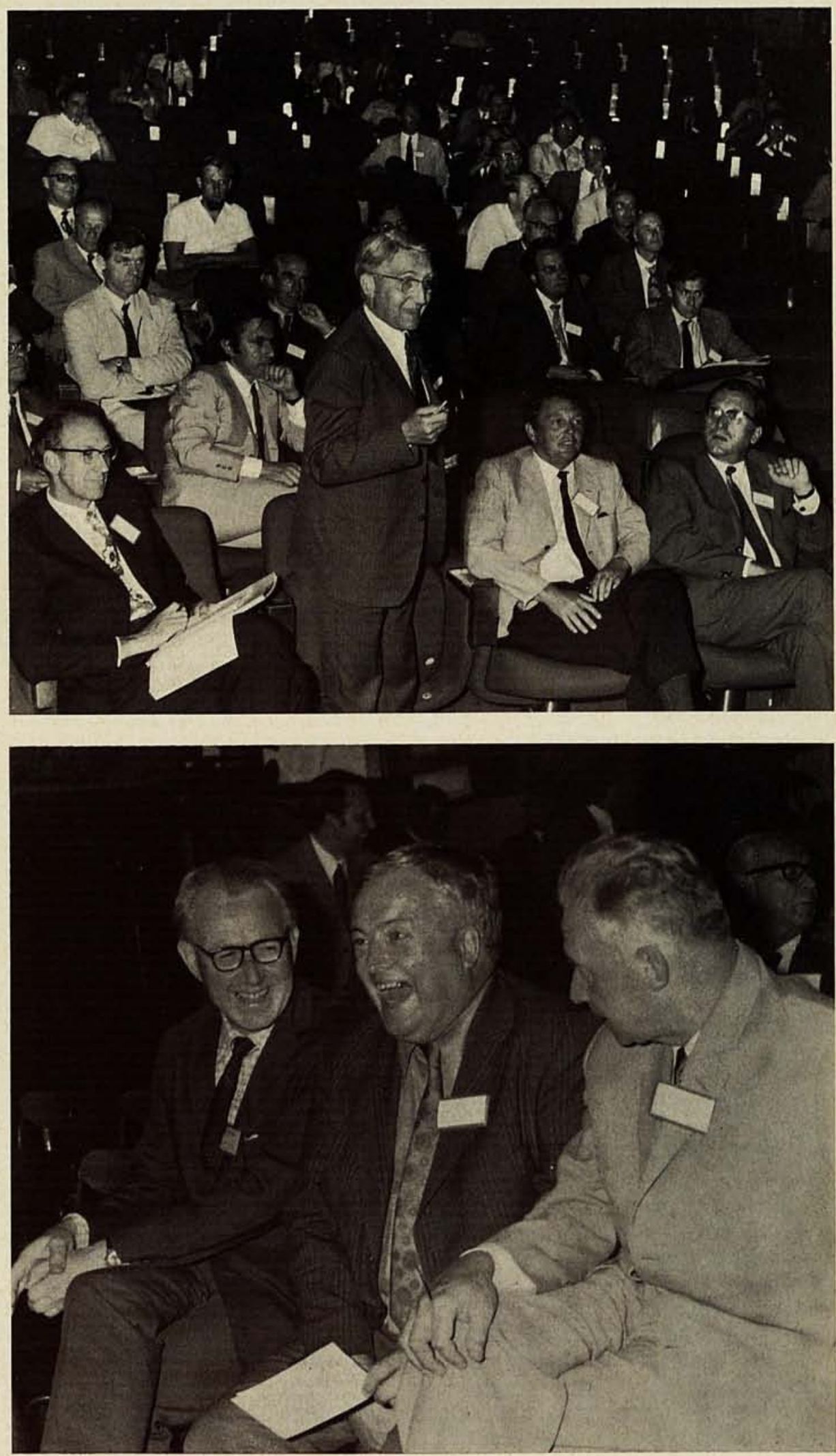